\title{
BMJ Open Are risk factors for preterm and early- term live singleton birth the same? A population-based study in France
}

\author{
Marie Delnord, Béatrice Blondel, Caroline Prunet, Jennifer Zeitlin
}

To cite: Delnord M, Blondel B, Prunet $\mathrm{C}$, et al. Are risk factors for preterm and earlyterm live singleton birth the same? A population-based study in France. BMJ Open 2018;8:e018745. doi:10.1136/ bmjopen-2017-018745

- Prepublication history for this paper is available online. To view these files, please visit the journal online (http://dx.doi. org/10.1136/bmjopen-2017018745).

Received 26 July 2017 Revised 21 November 2017 Accepted 12 December 2017

Check for updates

INSERM UMR 1153, Obstetrical, Perinatal and Pediatric Epidemiology Research Team (Epopé), Centre for Epidemiology and Statistics Sorbonne Paris Cité, DHU Risks in Pregnancy, Paris Descartes University, Paris, France

Correspondence to

Dr. Marie Delnord;

Marie.delnord@inserm.fr

\section{ABSTRACT}

Objectives To investigate whether risk factors for preterm ( $<37$ weeks gestation) and early-term birth (37 and 38 weeks gestation) are similar.

Design Nationally representative cross-sectional study of births.

Setting France in 2010.

Participants Live singleton births ( $n=14326)$.

Primary and secondary outcome measures Preterm and early-term birth rates overall and by mode of delivery (spontaneous and indicated). Risk factors were maternal sociodemographic characteristics, previous preterm birth, height, prepregnancy body mass index (BMI) and smoking, assessed using multinomial regression models with fullterm births 39 weeks and over as the reference group. Results There were $5.5 \%$ preterm and $22.5 \%$ early-term births. Common risk factors were: a previous preterm delivery (adjusted relative risk ratio (aRRR) 8.2 (95\% Cl 6.2 to 10.7 ) and aRRR 2.4 (95\% Cl 2.0 to 3.0), respectively), short stature, underweight (overall and in spontaneous deliveries), obesity (in indicated deliveries only), a low educational level and Sub-Saharan African origin. In contrast, primiparity was a risk factor only for preterm birth, aRRR 1.8 (95\% Cl 1.5 to 2.2), while higher parity was associated with greater risk of early-term birth.

Conclusions Most population-level risk factors were common to both preterm and early-term birth with the exception of primiparity, and BMI which differed by mode of onset of delivery. Our results suggest that preterm and early-term birth share similar aetiologies and thus potentially common strategies for prevention.

\section{INTRODUCTION}

Preterm birth, defined as birth before 37 weeks of gestation, is a leading cause of perinatal mortality and morbidity. In Europe, preterm infants represent $75 \%$ of all neonatal deaths and $60 \%$ of all infant deaths. ${ }^{1}$ They are at risk of short-term and long-term neurocognitive and motor impairments, and display higher rates of chronic disease and premature death compared with term infants. ${ }^{2}$ The prevention of preterm birth is a global priority; however, preterm births are not the only gestational age (GA) subgroup at risk of adverse health outcomes. ${ }^{34}$ Compared with being born full term, defined as between

\section{Strengths and limitations of this study}

- We had detailed information on prenatal social and demographic characteristics collected using a standardised maternal interview in a representative sample of births in France.

- We had few missing data for which we corrected using multiple imputation.

- We used multinomial regression to estimate preterm and early-term birth adjusted relative risk ratios and their $95 \% \mathrm{Cl}$ by maternal characteristics using births reaching full term (ie, births 39 weeks and over) as the reference.

- Because very preterm births represented $0.6 \%$ of births in our sample, we do not report associations by preterm gestational age subgroups.

- Our sample size may have been too small to detect low-to-moderate associations in less prevalent subgroups of women, such as heavy smokers, for instance.

39 and 41 weeks, early-term birth at 37 and 38 weeks is associated with higher risks of neonatal mortality, more intensive care unit admissions, ${ }^{4}$ and higher health-related costs well into childhood for obstructive airway diseases, visual and motor disabilities. ${ }^{5}$

There are large differences in rates and trends of preterm and early-term births among countries with similar levels of development. $^{167}$ In Europe in 2010, live singleton preterm birth rates ranged between $4.1 \%$ and $8.2 \%$ while early-term rates ranged between $15.6 \%$ and $30.8 \%^{8}$; such heterogeneity across countries suggests that rate reductions may be possible. However, despite the significant public health burden, ${ }^{4-11}$ little progress has been made in decreasing the number of these early births. ${ }^{6} 1213$ The latest French recommendations for the prevention of spontaneous preterm birth (sPTB) focus on smoking cessation and on interventions for women with high-risk pregnancies (ie, cerclage, progesterone), but conclude that high-quality evidence does not exist for other preventive strategies ${ }^{14}$; this is partially due to 
the low predictive accuracy of diagnostic tools. ${ }^{12}$ As for early-term birth, prevention efforts are recent, with a focus by professional societies in the USA on the reduction of indicated early-term deliveries for non-medical reasons. ${ }^{15}$

More research on the aetiology of early delivery is required to orient prevention efforts and practice. There is recent evidence that in high-income countries, moderate and late preterm birth rates are associated with rates of early-term birth. ${ }^{8}$ Positive associations between preterm and early-term birth country rates suggest that common population-level determinants could underpin shifts in the GA distribution towards early delivery. Known maternal characteristics that contribute significantly to preterm birth rates and trends within countries include maternal age, underweight, obesity and socioeconomic status. ${ }^{16}$ Early-term and late-preterm births also have worse neonatal outcomes compared with full-term births. ${ }^{17}$ However, what is not known is which maternal characteristics related to preterm birth risk ${ }^{1121618}$ could also relate to early-term birth. ${ }^{19}$ Thus, in this study we aimed to identify maternal population determinants of preterm and early-term birth overall and by mode of onset of delivery, that is, spontaneous or indicated, using nationally representative data from the French National Perinatal Survey in 2010.

\section{MATERIALS AND METHODS}

The French National Perinatal Survey 2010 (Enquête Nationale Périnatale, ENP) is based on a representative sample of births in France. The National Perinatal Surveys have been conducted periodically since 1995 and constitute part of the routine health information system for the surveillance of mothers and newborns in France. ${ }^{20}$ Data are collected on all live and stillbirths starting at 22 weeks of gestation or weighing at least $500 \mathrm{~g}$ over the course of 1 week in all public and private maternity units. In 2010, there were 535 maternity units operating in metropolitan France of which one refused to participate. ${ }^{20}$ For this study, we included singleton pregnancies ending in a live birth with a GA of 22 weeks of gestation or over ( $n=14326$ pregnant women). Multifetal pregnancies and stillbirths were excluded because of differences in delivery practices and aetiology for these births.

Survey items on mothers' demographic characteristics (eg, maternal age, parity), socioeconomic status (eg, level of education), prenatal care and behaviours were collected during interviews with midwives or nurses in the postpartum ward. Other data on the delivery and newborn health were abstracted from the medical records by medical staff, and include information on the mode of onset of delivery, pre-existing maternal medical conditions (hypertension, diabetes), as well as routine indicators of neonatal health at birth. ${ }^{20}$ We defined indicated deliveries as those with a provider-initiated mode of onset, that is, either induction of labour or prelabour caesarean section. Although there may have been differences in the distribution of maternal characteristics by region, our total sample size precluded us carrying out more detailed analyses (24 regions in total, $\mathrm{N}$ minimum $=58$ and $\mathrm{N}$ maximum $=1312$ live singleton births).

Our main outcomes were preterm and early-term birth. These were defined, respectively, as births 22-36 completed weeks of gestation and 37-38 completed weeks overall and by mode of onset (spontaneous or indicated). GA was based on the best obstetrical estimate. In France, nearly all women have a first trimester ultrasound for dating the pregnancy. ${ }^{20}$ The upper limit of GA included in the sample was 44 weeks, but very few deliveries were post-term ( $\mathrm{n}=49,0.4 \%$ at 42 weeks and over). We also do not report associations by preterm GA subgroups, in particular for very preterm births $(\mathrm{n}=122,0.9 \%)$.

We selected risk factors based on a scoping review of the scientific literature, including recent research on preterm birth risk factors in France. ${ }^{18}{ }^{21}$ Some preterm birth exposures that were available in the French National Perinatal Survey were omitted from our study because of their low prevalence in the sample (ie, use of fertility treatments: $<4 \%$, diabetes: $<2 \%$ and chronic hypertension: $2 \%$ ); however, women with these conditions were not excluded from the study.

We included the following variables in our analysis: maternal age $(<20,20-24,25-29,30-34, \geq 35$ years old), parity $(1,2-3,4+)$, previous preterm birth, nationality (French, Other European, North African, Sub-Saharan African, Other), maternal height presented in quartiles (Q1: $100-160 \mathrm{~cm}$, Q2: $161-165 \mathrm{~cm}$, Q3: $166-168 \mathrm{~cm}$, Q4:169-190 cm), prepregnancy body mass index (BMI in $\mathrm{kg} / \mathrm{m} 2$ ), defined as underweight, normal, overweight and obese women for BMIs <18.5, 18.5-24.9, 25-29.9, $\geq 30$, respectively, level of education, and smoking during the third trimester. Level of completed education was defined based on the International Standard Classification of Education (ISCED) 2011 classification: low educational level ISCED 0-2 (ie, up to lower secondary education completed), medium educational level ISCED 3-5 (ie, upper secondary education or short cycle tertiary education completed), high educational level ISCED 6-7 (bachelors' equivalent or higher). BMI is a measure of body mass that is independent of height in adults; therefore, both variables were included in the study. ${ }^{22}$

The National Council on Statistical Information (Comité du Label) and the French Commission on Information Technology and Liberties approved the French National Perinatal Surveys (ENP 2010).

\section{Analysis strategy}

We first compared the distributions of preterm and earlyterm births by maternal characteristics. We included all maternal exposures hypothesised to be associated with preterm delivery in the multivariable analyses. ${ }^{18}$ We used multinomial regression to estimate preterm and earlyterm birth adjusted relative risk ratios (aRRRs) and their 95\% CIs by maternal characteristics using births reaching full term (ie, births 39 weeks and over) as the reference. 
aRRRs are similar to adjusted ORs in binary logistic regression.

In the mode of onset analyses, we computed relative risk ratios of spontaneous and indicated preterm and early delivery using the same full-term reference population (ie, all births 39 weeks and over, regardless of mode of onset). We used this reference population as we considered spontaneous and indicated births as two subtypes of our outcome (early delivery). Indicated deliveries at full term are principally for prolonged pregnancy, previous caesarean section and can be based on maternal request, indications which are much less common before 39 weeks. ${ }^{23}{ }^{24}$ Data were analysed using STATA V.13.0 software (StataCorp, College Station, Texas, USA).

There were 14326 live singleton births in the survey of which 65 were missing GA data. We had less than $1 \%$ missing data on mode of onset of labour (ie, spontaneous or provider-initiated delivery) and less than 5\% missing sociodemographic data (ie, nationality and level of education). There were $4 \%$ missing data on previous preterm birth and $6 \%$ missing on anthropometric characteristics (ie, height or BMI). Although individual proportions of missing data were low, complete cases were only $86 \%$ of the total and therefore we imputed missing values (except the outcome) using multivariate imputation by chained equations. We performed 100 imputations using all available covariates. ${ }^{25}$ Descriptive and multivariate analyses were done on the imputed dataset. Because data were imputed, we used F-tests to look at differences in the distributions of maternal characteristics by GA subgroup. ${ }^{26}$

\section{RESULTS}

Table 1 provides descriptive statistics on our sample. We included 14261 live singleton pregnancies with GA data available. The overall rate of preterm birth was $5.5 \%$ and early-term birth was $22.6 \%$. In the reference population of women with a full-term birth, $2.4 \%$ were aged under 20 and $18.3 \%$ over 35 years of age; $44.1 \%$ were primiparous and $6.9 \%$ were parity four or more; $2.2 \%$ had a previous preterm birth, $7.8 \%$ were underweight, $9.4 \%$ were overweight and $16.4 \%$ smoked in the third trimester of pregnancy. The risk profiles of mothers with a preterm and early-term infant were different. These mothers were more likely to be older, have a previous preterm birth, be of shorter stature, with a lower level of education and smoke. Mothers with a preterm birth were more likely to be primipara whereas mothers with an early-term birth were more likely to be multipara, compared with mothers with a term birth.

In multinomial multivariable models, most of these associations persisted; common population determinants for preterm and early-term birth were: a previous preterm birth, shorter stature, underweight, sub-Saharan nationality and a low level of education. There were some differences in the impact of these risk factors: a previous preterm birth was a stronger risk factor for preterm birth than early-term birth (aRRR 8.2 vs 2.4, respectively); maternal underweight and sub-Saharan nationality were also stronger risk factors for preterm compared with earlyterm birth. Primiparae were at risk for preterm birth only (aRRR 1.8 (95\% CI 1.5 to 2.2)), whereas grand multiparae (parity 4+) were at higher risk of early-term birth. After adjustment, advanced maternal age and smoking during the third trimester were no longer associated with increased risks of delivery before 39 weeks.

In table 2, we display the associations between sPTB and early-term births by maternal characteristics. Out of all births, $2.8 \%$ were sPTBs and $13.6 \%$ were spontaneous early-term births. Common risk factors were: a previous preterm birth, short stature, maternal underweight, foreign nationality (ie, other European) and a low level of education. There were some differences in the impact of these risk factors. Underweight was a stronger risk factor for sPTB than early-term birth: aRRR 1.9 (95\% CI 1.4 to 2.6 ) versus aRRR 1.3 (95\% CI 1.1 to 1.5 ), respectively, and overweight women displayed a reduced risk of spontaneous early-term delivery. Primiparae were at risk of preterm birth but not early-term birth. Smoking during the third trimester was associated with a moderately increased risk of spontaneous preterm delivery, although the CI included 1: aRRR 1.5 (95\% CI 1.0 to2.2). The aRRR was lower and non-significant for early-term birth: 1.2 (95\% CI 0.9 to 1.5$)$.

In table 3, we display the associations between indicated preterm and early-term birth by maternal characteristics. Out of all births, $2.6 \%$ were indicated preterm deliveries and $8.8 \%$ were indicated early-term deliveries. Most risk factors were common to indicated preterm and early-term birth including: advanced maternal age, a previous preterm birth, short stature, obesity (aRRR 1.6 (95\% CI 1.1 to 2.2) preterm, and aRRR 1.7 (95\% CI 1.4 to 2.0) early term), sub-Saharan African origin (aRRR 2.2 (95\% CI 1.4 to 3.5) preterm and aRRR 1.6 (95\% CI 1.2 to 2.2) for early term), and a low level of education, after adjusting on all other covariates. Primiparae were only at risk for indicated preterm birth, aRRR 2.1 (95\% CI 1.6 to 2.7); while parity 4+ was associated with greater risk of indicated early-term birth, aRRR 1.3 (95\% CI 1.1 to 1.6).

When we compare findings from our mode of onset analyses, tables 2 and 3 show that risk factors for delivery before 39 weeks are the same in spontaneous preterm and early-term deliveries, and indicated preterm and earlyterm deliveries - with the exception of BMI. Underweight was a risk factor for spontaneous delivery before 39 weeks (aRRR 1.9 (95\% CI 1.4 to 2.6) for preterm and aRRR 1.3 (95\% CI 1.1 to 1.5 ) for early term), whereas overweight was a risk factor for indicated delivery before 39 weeks (aRRR 1.6 (95\% CI 1.1 to 2.2) preterm, and aRRR 1.7 (95\% CI 1.4 to 2.0 ) early term).

\section{DISCUSSION}

Our study provides new insight into the population determinants of preterm and early-term birth by mode 
Table 1 Associations between maternal characteristics and risks of preterm ( $<37$ weeks) and early-term birth (37-38 weeks) using births reaching full term (ie, 39 weeks and over) as the reference in a representative sample of births in France in 2010

\begin{tabular}{|c|c|c|c|c|c|c|c|c|c|}
\hline & & \multirow{2}{*}{$\begin{array}{l}<37 \text { weeks } \\
\text { GA \% } \\
\mathrm{n}=782 \\
\end{array}$} & \multirow{2}{*}{$\begin{array}{l}\text { 37-38 weeks } \\
\text { GA \% } \\
\mathrm{n}=3010\end{array}$} & \multirow{2}{*}{$\begin{array}{l}\geq 39 \text { weeks } \\
\text { GA \% } \\
n=10269\end{array}$} & \multirow[b]{2}{*}{ P value* } & \multicolumn{2}{|c|}{$<37$ weeks GA } & \multicolumn{2}{|c|}{ 37-38 weeks GA } \\
\hline & & & & & & aRRRs & $95 \% \mathrm{Cl}$ & aRRRs & $95 \% \mathrm{Cl}$ \\
\hline \multicolumn{10}{|l|}{ Maternal age (years) } \\
\hline$<20$ & 346 & 3.9 & 2.3 & 2.4 & 0.005 & 1.0 & 0.7 to 1.6 & 0.9 & 0.7 to 1.2 \\
\hline $20-24$ & 2078 & 16.3 & 14.5 & 14.5 & & 0.9 & 0.8 to 1.2 & 1.0 & 0.9 to 1.2 \\
\hline $25-29$ & 4737 & 32.8 & 31.7 & 33.7 & & Ref. & - & Ref. & - \\
\hline $30-34$ & 4380 & 27.9 & 30.1 & 31.1 & & 1.0 & 0.8 to 1.2 & 1.0 & 0.9 to 1.1 \\
\hline$\geq 35$ & 2720 & 19.1 & 21.4 & 18.3 & & 1.1 & 0.9 to 1.4 & 1.2 & 1.0 to 1.3 \\
\hline Parity & & & & & $<0.001$ & & & & \\
\hline 1 & 6165 & 49.8 & 38.9 & 44.1 & & 1.8 & 1.5 to 2.2 & 0.9 & 0.8 to 1.0 \\
\hline $2-3$ & 6980 & 39.8 & 50.8 & 49.1 & & Ref. & & Ref. & - \\
\hline $4+$ & 1116 & 10.4 & 10.3 & 6.9 & & 1.2 & 0.9 to 1.6 & 1.2 & 1.1 to 1.4 \\
\hline Previous preterm birth & & & & & $<0.001$ & & & & \\
\hline No & 13740 & 86.6 & 94.1 & 97.8 & & Ref. & - & Ref. & - \\
\hline Yes & 521 & 13.4 & 5.9 & 2.2 & & 8.2 & 6.2 to 10.7 & 2.4 & 2.0 to 3.0 \\
\hline Maternal height (cm) & & & & & $<0.001$ & & & & \\
\hline Q1: $100-160$ & 4365 & 37.7 & 34.6 & 28.8 & & 1.4 & 1.1 to 1.7 & 1.4 & 1.2 to 1.6 \\
\hline Q2: 161-165 & 4143 & 25.9 & 29.9 & 29.0 & & 1.0 & 0.8 to 1.2 & 1.2 & 1.1 to 1.4 \\
\hline Q3: $166-168$ & 2440 & 15.2 & 15.2 & 17.9 & & 0.9 & 0.7 to 1.2 & 1.0 & 0.9 to 1.2 \\
\hline Q4: 169-190 & 3313 & 21.3 & 20.4 & 24.3 & & Ref. & - & Ref. & - \\
\hline Prepregnancy BMI† & & & & & 0.307 & & & & \\
\hline$<18.5$ & 1177 & 12.9 & 8.5 & 7.8 & & 1.7 & 1.3 to 2.2 & 1.1 & 1.0 to 1.3 \\
\hline $18.5-25.9$ & 9190 & 59.9 & 63.6 & 65.0 & & Ref. & - & Ref. & - \\
\hline $25-29.9$ & 2472 & 15.5 & 16.6 & 17.7 & & 0.9 & 0.7 to 1.1 & 0.9 & 0.8 to 1.0 \\
\hline$\geq 30$ & 1422 & 11.7 & 11.2 & 9.4 & & 1.2 & 1.0 to 1.6 & 1.1 & 1.0 to 1.3 \\
\hline Nationality & & & & & 0.043 & & & & \\
\hline French & 12360 & 84.0 & 86.3 & 87.0 & & Ref. & - & Ref. & - \\
\hline Other European & 470 & 4.2 & 3.3 & 3.2 & & 1.2 & 0.8 to 1.8 & 1.0 & 0.8 to 1.2 \\
\hline North African & 685 & 4.9 & 4.4 & 4.9 & & 1.1 & 0.7 to 1.5 & 0.8 & 0.7 to 1.0 \\
\hline Sub-Saharan Africa & 392 & 4.5 & 3.3 & 2.4 & & 1.8 & 1.2 to 2.6 & 1.3 & 1.0 to 1.6 \\
\hline Other & 354 & 2.5 & 2.7 & 2.4 & & 1.0 & 0.6 to 1.6 & 1.1 & 0.8 to 1.4 \\
\hline \multicolumn{10}{|l|}{ Level of education } \\
\hline Low ISCED 0-2 & 4054 & 37.5 & 31.9 & 26.7 & $<0.001$ & 1.7 & 1.3 to 2.1 & 1.2 & 1.1 to 1.4 \\
\hline Medium ISCED 3-5 & 5883 & 38.8 & 40.6 & 41.7 & & 1.2 & 1.0 to 1.5 & 1.1 & 1.0 to 1.2 \\
\hline High ISCED 6+ & 4324 & 23.7 & 27.6 & 31.7 & & Ref. & - & Ref. & - \\
\hline $\begin{array}{l}\text { Smoking (number of } \\
\text { cigarettes/day during } \\
\text { the third trimester) }\end{array}$ & & & & & $<0.001$ & & & & \\
\hline 0 & 11814 & 79.1 & 81.4 & 83.6 & & Ref. & - & Ref. & - \\
\hline $1-9$ & 1757 & 13.9 & 12.8 & 12.1 & & 1.0 & 0.8 to 1.3 & 1.0 & 0.9 to 1.2 \\
\hline$\geq 10$ & 690 & 7.0 & 5.8 & 4.4 & & 1.3 & 0.9 to 1.8 & 1.1 & 0.9 to 1.4 \\
\hline
\end{tabular}

Ref. indicates the reference category for each variable.

${ }^{*}$ F-test.

†BMI. Body mass index in $\mathrm{kg} / \mathrm{m} 2$

aRRR, adjusted relative risk ratio; BMI, body mass index; GA, gestational age; ISCED 2011, International Standard Classification of Education 2011. 
Table 2 Associations between maternal characteristics and risks of spontaneous preterm ( $<37$ weeks) and early-term birth (37-38 weeks) using births reaching full term (ie, 39 weeks and over, $n=10269$ ) as the reference in a representative sample of births in France in 2010

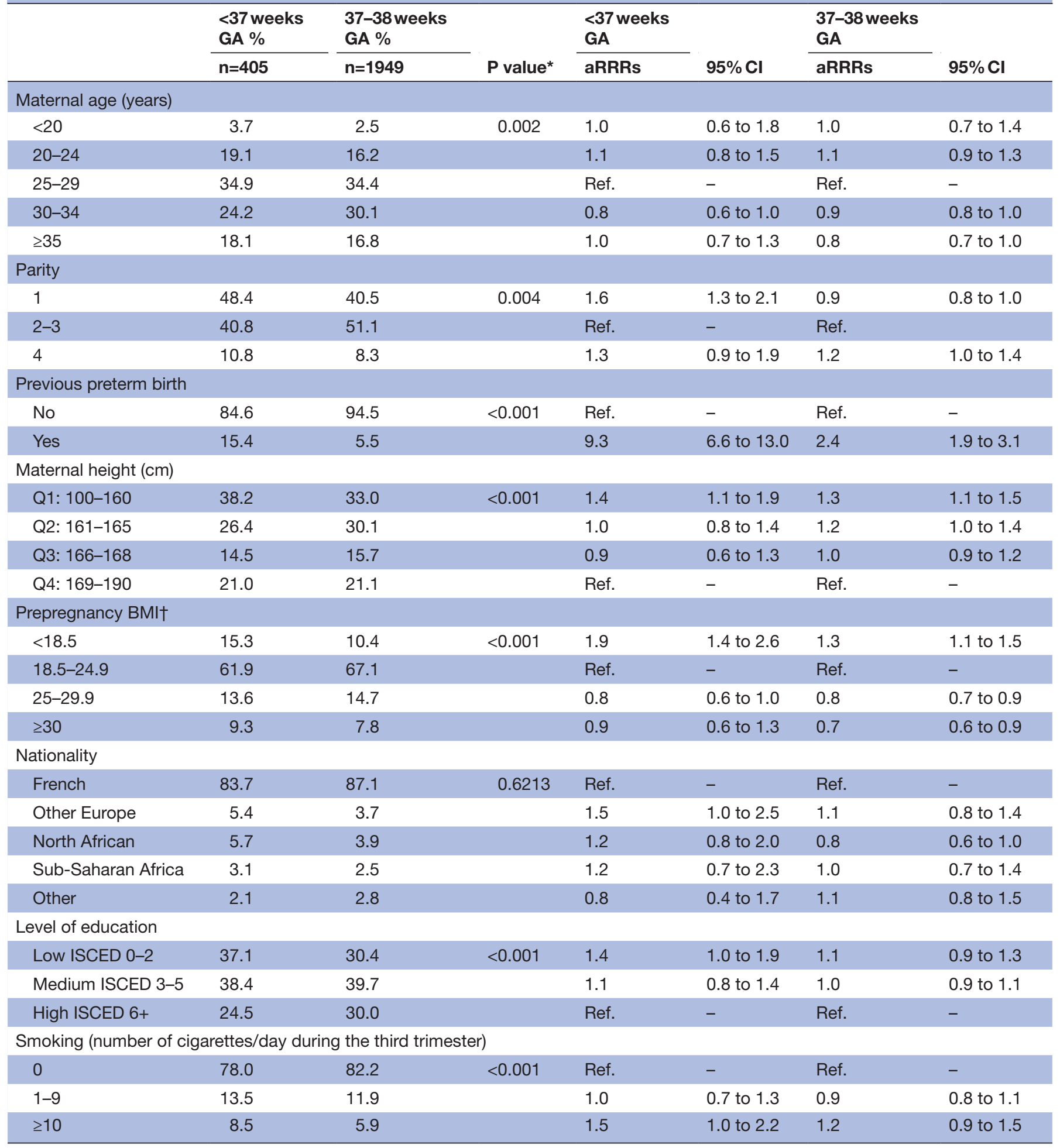

Ref. indicates the reference category for each variable.

${ }^{*}$ F-test.

†BMI.Body mass index in $\mathrm{kg} / \mathrm{m} 2$.

aRRR, adjusted relative risk ratio; BMI, body mass index; GA, gestational age; ISCED 2011, International Standard Classification of Education 2011. 
Table 3 Associations between maternal characteristics and risks of indicated preterm (<37 weeks) and early-term birth (3738 weeks) using births reaching full term (ie, 39 weeks and over, $n=10269$ ) as the reference in a representative sample of births in France in 2010

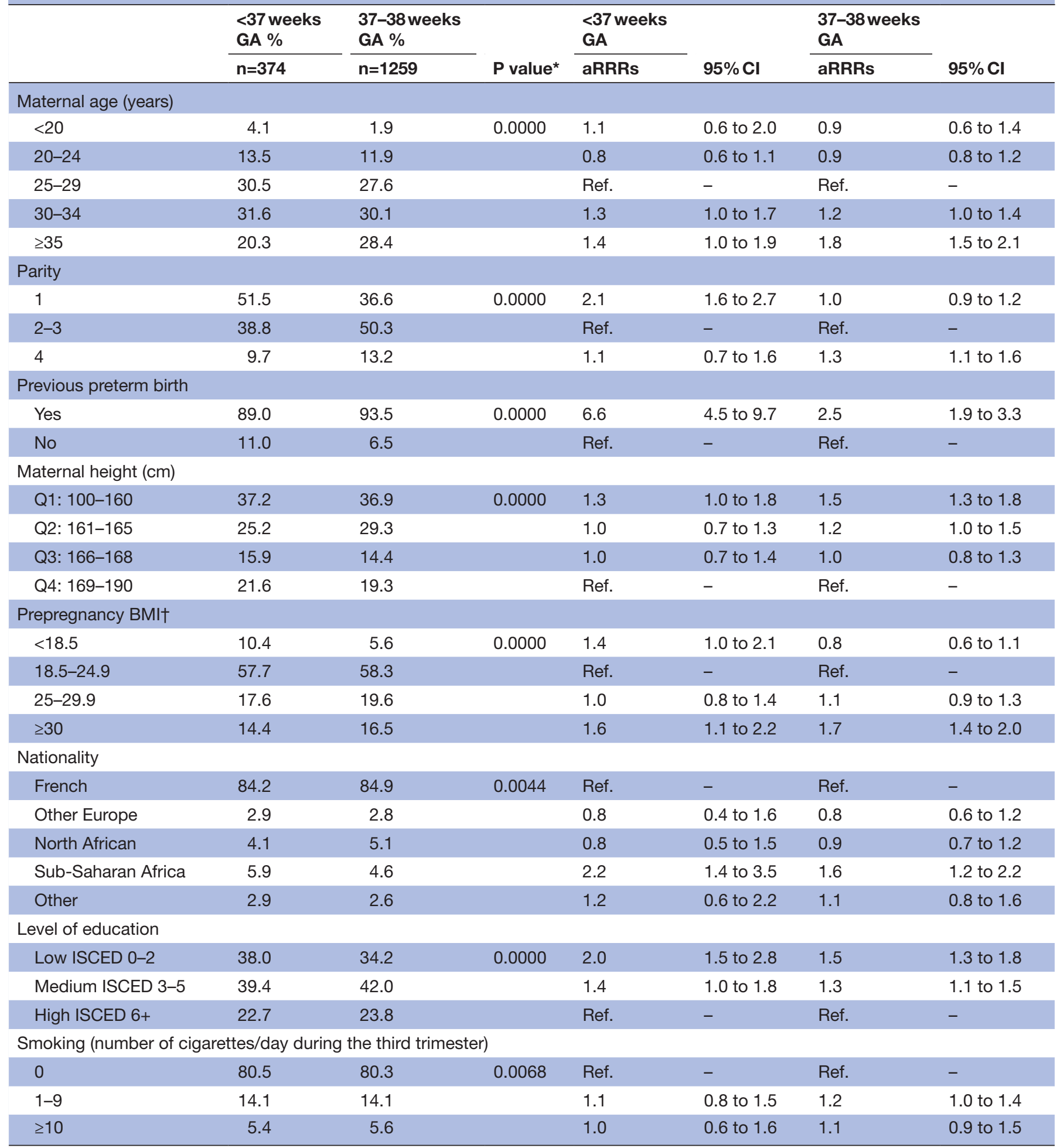

Ref. indicates the reference category for each variable.

${ }^{*}$ F-test.

†BMI. Body mass index in $\mathrm{kg} / \mathrm{m} 2$.

aRRR, adjusted relative risk ratio; BMI, body mass index; GA, gestational age; ISCED 2011, International Standard Classification of Education 2011. 
of onset of delivery. We identified shared risk factors for delivery before 39 weeks which were: a previous preterm birth, short stature, a low level of education, underweight (overall and in spontaneous deliveries), obesity (in indicated deliveries only) and foreign origin (for other European and sub-Saharan nationals). The impact of most risk factors was greater for preterm birth compared with earlyterm birth, and primiparity was a risk factor for preterm birth but not early-term birth.

A strength of our study is the availability of detailed population-based information on prenatal, social and demographic characteristics collected using a standardised maternal interview in a representative sample of births in France. We had few missing data for which we corrected using multiple imputation. In this study, we focused on the broader population determinants of early delivery that contribute to overall rates of preterm and early-term birth in France. We conducted analyses for spontaneous and indicated deliveries separately to highlight potential differences in risk factors between these subtypes of preterm birth for which some medical maternal and fetal factors differ. ${ }^{27}$ We did not include pregnancy complications in our analyses as these constitute intermediate variables between population characteristics and the risk of preterm and early-term deliveries. ${ }^{28} 29$

Our study also has some limitations. Our sample size may have been too small to detect low-to-moderate associations in less prevalent subgroups of women, such as heavy smokers, for instance. Similarly, we did not analyse some risk factors available in our dataset which had a low prevalence (ie, pre-existing medical conditions: diabetes, hypertension) or carry out analyses by region although there may have been differences in the distribution of maternal characteristics. We did not carry out separate analyses for very preterm births, and risk factors for this vulnerable subpopulation may differ from those for moderate and late preterm births at 32-36 weeks of gestation. Finally, we did not correct for multiple comparisons to maintain adequate power to carry out the study. ${ }^{30}$

The strongest single predictor of both preterm and early-term delivery was a previous preterm birth (overall and by mode of onset of delivery), as confirmed in other population-based studies ${ }^{31} 32$ and a recent systematic review which showed a $30 \%$ risk of recurrent $\mathrm{sPTB}$ following $\mathrm{SPTB}$ in singleton pregnancies. ${ }^{33}$ In contrast, first-time mothers were more likely to deliver preterm, but not early term indicating that the shape of the risk distribution for early delivery in primiparae may slightly differ from the overall GA distribution which peaks around 38-40 weeks of gestation. Fertility trends determining the proportion of primiparous women may therefore contribute to differences in preterm and early-term birth rates across countries.

Sociodemographic characteristics, measured by a lower level of education and mother's nationality, were also associated with earlier delivery overall and by mode of onset of delivery. Maternal educational level is a well-documented risk factor for preterm birth risk and recent findings from Canada have shown an association with early-term birth. ${ }^{34-36}$ Exposures related to mothers' general quality of life and well-being (ie, living and employment conditions, air pollution, exposure to stress) could mediate the association with social status via physiological pathways. ${ }^{37-41}$ In France, Prunet et al showed that social status was associated with preterm birth risk independently of use of medical care during pregnancy. ${ }^{18}$ As for the association with foreign origin, our results are consistent with the literature showing higher risks of preterm birth among women from sub-Saharan Africa. ${ }^{42}$

There were common anthropometric determinants of delivery before 39 weeks overall, although there were differences by mode of onset of delivery. Our findings confirm previous research on the association between preterm birth and short stature ${ }^{4344}$ and we provide new evidence on the association with early-term birth. Thinness is often associated with SPTB but the association between GA and overweight is less clear. ${ }^{45-47} \mathrm{~A}$ greater prevalence of comorbidities in obese women could contribute to the excess in indicated delivery, ${ }^{48}$ which we observed. Whereas, the decreased risk of spontaneous preterm and early-term delivery in women with BMIs over 30 could be due to specific delivery practices, and greater levels of obstetrical interventions for obese women in general. ${ }^{49}$

Finally, smoking and advanced maternal age are traditionally cited as preterm birth risk factors ${ }^{50} 51$; while there was an increased risk for SPTB in heavy smokers, and an increased risk for indicated preterm and early-term delivery in mothers over 35 , associations with either variable in the overall analyses were not statistically significant. Previous data from France also showed a limited impact of smoking on overall preterm birth risk, whereas associations were stronger in studies from other countries. ${ }^{20} 21$

Our findings showing common risk patterns for preterm and early-term births suggest a shared aetiology for these births overall, with some exceptions for primiparous women and by mode of onset of delivery for BMI. These results raise questions about the appropriate definition of preterm birth, and the GA threshold which should be used. ${ }^{52}$ Our findings by mode of onset of delivery are also consistent with two reports documenting shared pregnancy complications for spontaneous preterm and early-term deliveries. ${ }^{28} 29$ Delivery following spontaneous labour even close to full term may be a result of pathological processes, ${ }^{28}$ with evidence in the literature of a slightly more heterogeneous aetiology for medically indicated late-preterm and early-term phenotypes (ie, anaemia and gastrointestinal disease are associated with late preterm but not early-term delivery). ${ }^{29}$ Future research associating maternal exposures with pregnancy complications such as diabetes mellitus, infection and inflammation, placental ischaemia, polyhydramnios and oligohydramnios, which are related to spontaneous and indicated preterm and early-term births could provide insight into the mechanisms underpinning early delivery. ${ }^{28}$ 
In conclusion, our population-based study shows that there are several shared maternal prenatal and sociodemographic risk factors for delivery before full term (ie, 39 weeks and over). Because strategies to reduce individual risk of preterm birth have had a limited impact on overall rate reductions, ${ }^{12}$ investing in broader population-based interventions may be justified, including those targeting maternal prepregnancy BMI and the social determinants of health. ${ }^{48}$ Moreover, due to the large volume of births at 37-38 weeks, even small point percentage reductions are likely to impact on health systems' expenditures and use of educational and social services. For instance, each additional week of gestation after 35 weeks reduces specific delays in communication, personal-social, fine motor and problem-solving skills up until 24 months of age, and the population attributable fraction for poor achievement in school is highest among early-term births. ${ }^{53} 54$ The existence of shared risk factors for both GA subgroups and the greater number of early-term births compared with preterm births provides greater power to investigate the mechanisms leading to early delivery, and supports the use of a broader paradigm for preterm birth prevention and research.

Contributors $\mathrm{MD}, \mathrm{BB}$ and $\mathrm{JZ}$ contributed to the study design and interpretation of the data. MD, BB and CP participated in the data collection and analysis. MD and JZ drafted the manuscript, BB provided critical revisions. All authors have read and approved the final version of the manuscript.

Funding This work was supported by Paris Descartes University, Paris, France. The French National Perinatal Survey 2010 was funded by the French Ministry of Health.

\section{Competing interests None declared.}

\section{Patient consent Obtained.}

Provenance and peer review Not commissioned; externally peer reviewed.

Data sharing statement Instructions for applying for public access data from the French National Perinatal Survey are available on request from the authors.

Author note The National Council on Statistical Information (Comité du Label) and the French Commission on Information Technology and Liberties (CNIL) approved the French National Perinatal Survey 2010 (Enquête Nationale Périnatale 2010).

Open Access This is an Open Access article distributed in accordance with the Creative Commons Attribution Non Commercial (CC BY-NC 4.0) license, which permits others to distribute, remix, adapt, build upon this work non-commercially, and license their derivative works on different terms, provided the original work is properly cited and the use is non-commercial. See: http://creativecommons.org/ licenses/by-nc/4.0/

(c) Article author(s) (or their employer(s) unless otherwise stated in the text of the article) 2018. All rights reserved. No commercial use is permitted unless otherwise expressly granted.

\section{REFERENCES}

1. Euro-Peristat project with SCPE and EUROCAT. European Perinatal Health Report - The health and care of pregnant women and babies in Europe in 2010, 2013.

2. Blencowe $\mathrm{H}$, Cousens $\mathrm{S}$, Chou D, et al. Born too soon: the global epidemiology of 15 million preterm births. Reprod Health 2013;10(Suppl 1):S2

3. Zhang X, Kramer MS. Variations in mortality and morbidity by gestational age among infants born at term. $J$ Pediatr 2009;154:358-62.

4. Sengupta S, Carrion V, Shelton J, et al. Adverse neonatal outcomes associated with early-term birth. JAMA Pediatr 2013;167:1053-9.
5. Helle E, Andersson S, Häkkinen U, et al. Morbidity and health care costs after early term birth. Paediatr Perinat Epidemiol 2016;30:533-40.

6. Richards JL, Kramer MS, Deb-Rinker P, et al. Temporal Trends in Late Preterm and Early Term Birth Rates in 6 High-Income Countries in North America and Europe and Association With Clinician-Initiated Obstetric Interventions. JAMA 2016;316:410-9.

7. Zeitlin J, Szamotulska K, Drewniak N, et al. Preterm birth time trends in Europe: a study of 19 countries. BJOG 2013;120:1356-65.

8. Delnord M, Mortensen L, Hindori-Mohangoo AD, et al. International variations in the gestational age distribution of births: an ecological study in 34 high-income countries. Eur J Public Health 2017:ckx131.

9. Jacob J, Lehne M, Mischker A, et al. Cost effects of preterm birth: a comparison of health care costs associated with early preterm, late preterm, and full-term birth in the first 3 years after birth. Eur $J$ Health Econ 2017;18:1041-6.

10. Saigal S, Doyle LW. An overview of mortality and sequelae of preterm birth from infancy to adulthood. Lancet 2008;371:261-9.

11. Crump C, Sundquist K, Winkleby MA, et al. 37-38 weeks) and mortality in young adulthood. Epidemiology 2013;24:270-6.

12. Chang $\mathrm{HH}$, Larson $\mathrm{J}$, Blencowe $\mathrm{H}$, et al. Preventing preterm births: analysis of trends and potential reductions with interventions in 39 countries with very high human development index. Lancet 2013;381:223-34.

13. Lawn JE, Kinney MV, Belizan JM, et al. Born too soon: accelerating actions for prevention and care of 15 million newborns born too soon. Reprod Health 2013;10(Suppl 1):S6.

14. Sentilhes L, Sénat MV, Ancel PY, et al. Prevention of spontaneous preterm birth: Guidelines for clinical practice from the French College of Gynaecologists and Obstetricians (CNGOF). Eur J Obstet Gynecol Reprod Biol 2017;210:217-24.

15. Anon. ACOG Committee Opinion No 579: Definition of term pregnancy. Obstet Gynecol 2013;122:1139-40.

16. Delnord M, Blondel B, Zeitlin J. What contributes to disparities in the preterm birth rate in European countries? Curr Opin Obstet Gynecol 2015;27:133-42.

17. Brown HK, Speechley KN, Macnab J, et al. Neonatal morbidity associated with late preterm and early term birth: the roles of gestational age and biological determinants of preterm birth. Int $\mathrm{J}$ Epidemiol 2014;43:802-14.

18. Prunet C, Delnord M, Saurel-Cubizolles MJ, et al. Risk factors of preterm birth in France in 2010 and changes since 1995: Results from the French National Perinatal Surveys. Journal de gynecologie, obstetrique et biologie de la reproduction 2016.

19. Raju TN. Moderately preterm, late preterm and early term infants: research needs. Clin Perinatol 2013;40:791-7.

20. Blondel B, Lelong N, Kermarrec M, et al. Trends in perinatal health in France from 1995 to 2010 . Results from the French National Perinatal Surveys. J Gynecol Obstet Biol Reprod 2012;41:e1-15.

21. Prunet $C$, Delnord M, Saurel-Cubizolles MJ, et al. Risk factors of preterm birth in France in 2010 and changes since 1995: Results from the French National Perinatal Surveys. J Gynecol Obstet Hum Reprod 2017;46:19-28.

22. Heymsfield SB, Heo M, Thomas D, et al. Scaling of body composition to height: relevance to height-normalized indexes. $A m ~ J$ Clin Nutr 2011;93:736-40.

23. Roman $\mathrm{H}$, Blondel $\mathrm{B}$, Bréart $\mathrm{G}$, et al. Do risk factors for elective cesarean section differ from those of cesarean section during labor in low risk pregnancies? J Perinat Med 2008;36:297-305.

24. Coulm B, Blondel B, Alexander $\mathrm{S}$, et al. Elective induction of labour and maternal request: a national population-based study. BJOG 2016;123:2191-7.

25. Graham JW, Olchowski AE, Gilreath TD. How many imputations are really needed? Some practical clarifications of multiple imputation theory. Prev Sci 2007;8:206-13.

26. van Ginkel JR, Kroonenberg PM. Analysis of variance of multiply imputed data. Multivariate Behav Res 2014;49:78-91.

27. Savitz DA, Dole N, Herring AH, et al. Should spontaneous and medically indicated preterm births be separated for studying aetiology? Paediatr Perinat Epidemiol 2005;19:97-105.

28. Brown HK, Speechley KN, Macnab J, et al. Biological determinants of spontaneous late preterm and early term birth: a retrospective cohort study. BJOG 2015;122:491-9.

29. Brown HK, Speechley KN, Macnab J, et al. Maternal, fetal, and placental conditions associated with medically indicated late preterm and early term delivery: a retrospective study. BJOG 2016;123:763-70.

30. Feise RJ. Do multiple outcome measures require $p$-value adjustment? BMC Med Res Methodol 2002;2:8.

31. Yang J, Baer RJ, Berghella V, et al. Recurrence of preterm birth and early term birth. Obstet Gynecol 2016;128:364-72. 
32. Ferrero DM, Larson J, Jacobsson B, et al. Cross-Country Individual Participant Analysis of 4.1 Million Singleton Births in 5 Countries with Very High Human Development Index Confirms Known Associations but Provides No Biologic Explanation for 2/3 of All Preterm Births. PLoS One 2016;11:e0162506.

33. Phillips C, Velji Z, Hanly C, et al. Risk of recurrent spontaneous preterm birth: a systematic review and meta-analysis. BMJ Open 2017;7:e015402.

34. Auger N, Leduc L, Naimi Al, et al. Delivery at term: impact of University education by week of gestation. J Obstet Gynaecol Can 2016;38:118-24.

35. Oftedal AM, Busterud K, Irgens LM, et al. Socio-economic risk factors for preterm birth in Norway 1999-2009. Scand J Public Health 2016;44:587-92

36. Poulsen G, Strandberg-Larsen K, Mortensen L, et al. Exploring educational disparities in risk of preterm delivery: a comparative study of 12 European birth cohorts. Paediatr Perinat Epidemiol 2015;29:172-83.

37. Stieb DM, Chen L, Eshoul M, et al. Ambient air pollution, birth weight and preterm birth: a systematic review and meta-analysis. Environ Res 2012;117:100-11.

38. Staneva A, Bogossian F, Pritchard M, et al. The effects of maternal depression, anxiety, and perceived stress during pregnancy on preterm birth: a systematic review. Women Birth 2015;28:179-93.

39. Ncube CN, Enquobahrie DA, Albert SM, et al. Association of neighborhood context with offspring risk of preterm birth and low birthweight: a systematic review and meta-analysis of populationbased studies. Soc Sci Med 2016;153:156-64.

40. Zeitlin J, Combier E, Levaillant M, et al. Neighbourhood socioeconomic characteristics and the risk of preterm birth for migrant and non-migrant women: a study in a French district. Paediatr Perinat Epidemiol 2011;25:347-56.

41. Sørbye IK, Daltveit AK, Sundby J, et al. Preterm subtypes by immigrants' length of residence in Norway: a population-based study. BMC Pregnancy Childbirth 2014;14:239.

42. Gagnon AJ, Zimbeck M, Zeitlin J, et al. Migration to western industrialised countries and perinatal health: a systematic review. Soc Sci Med 2009;69:934-46.
43. Derraik JG, Lundgren M, Cutfield WS, et al. Maternal height and preterm birth: a study on 192,432 Swedish Women. PLoS One 2016;11:e0154304.

44. Han Z, Lutsiv O, Mulla S, et al. Maternal height and the risk of preterm birth and low birth weight: a systematic review and metaanalyses. J Obstet Gynaecol Can 2012;34:721-46.

45. Cnattingius S, Villamor E, Johansson S, et al. Maternal obesity and risk of preterm delivery. JAMA 2013;309:2362-70.

46. Torloni MR, Betrán AP, Daher S, et al. Maternal BMI and preterm birth: a systematic review of the literature with meta-analysis. J Matern Fetal Neonatal Med 2009;22:957-70.

47. Lynch AM, Hart JE, Agwu OC, et al. Association of extremes of prepregnancy BMI with the clinical presentations of preterm birth. Am J Obstet Gynecol 2014;210:428.e1-428.e9.

48. Gould JB, Mayo J, Shaw GM, et al. Swedish and American studies show that initiatives to decrease maternal obesity could play a key role in reducing preterm birth. Acta Paediatr 2014;103:586-91.

49. Hermann M, Le Ray C, Blondel B, et al. The risk of prelabor and intrapartum cesarean delivery among overweight and obese women: possible preventive actions. Am J Obstet Gynecol 2015;212:241. e1-241.e9.

50. Savitz DA, Murnane P. Behavioral influences on preterm birth: a review. Epidemiology 2010;21:291-9.

51. Luke B, Brown MB. Elevated risks of pregnancy complications and adverse outcomes with increasing maternal age. Hum Reprod 2007:22:1264-72.

52. Kirby RS, Wingate MS. Late preterm birth and neonatal outcome: is 37 weeks' gestation a threshold level or a road marker on the highway of perinatal risk? Birth 2010;37:169-71.

53. Dueker G, Chen J, Cowling C, et al. Early developmental outcomes predicted by gestational age from 35 to 41 weeks. Early Hum Dev 2016;103:85-90.

54. Searle AK, Smithers LG, Chittleborough CR, et al. Gestational age and school achievement: a population study. Arch Dis Child Fetal Neonatal Ed 2017;102:F409-F416. 